\title{
El matadero, de Esteban Echeverría. Tensiones discursivas en el camino hacia la emancipación literaria hispanoamericana
}

\author{
Eduardo BECERRA \\ Universidad Autónoma de Madrid
}

\begin{abstract}
RESUMEN
El siglo XIX hispanoamericano constituye un excelente campo de observación de los procesos que conducen a la literatura hacia su conformación moderna. En sociedades en las que todo estaba por hacer y donde al mismo tiempo las elites letradas sabían qué metas debían alcanzarse en el futuro, la literatura de este periodo refleja las contradicciones típicas de una larga transición donde su papel en el marco social sigue asumiendo actitudes civilizadoras a la espera de alcanzar la modernidad deseada. El matadero, de Esteban Echeverría, es quizá una de las obras de este periodo que mejor reflejan estas tensiones, no tanto en cuanto a su contenido sino especialmente en sus propias estrategias de escritura.
\end{abstract}

Palabras clave: Echeverría, El matadero, géneros literarios.

\section{El matadero of Esteban Echeverría. Discursive Tensions on the Road to Latin American Literary Emancipation}

\begin{abstract}
The nineteenth century Hispanic is an excellent field of view of the processes that lead to its formation to modern literature. In societies where everything was done and where at the same time the literate elites know what targets should be pursued in the future, the literature of this period reflects the contradictions typical of a long transition where his role in the social attitudes still assumes civilizing waiting to reach the desired currency. El matadero of Esteban Echeverría, is perhaps one of the works of this period that best reflect these tensions, not so much as to their content, but especially in their own writing strategies.
\end{abstract}

Keywords: Echeverría, El matadero, genres.

Aunque la literatura de Hispanoamérica del siglo XIX -algunos casos del Modernismo aparte- difícilmente podría ocupar lugares destacados en la República Mundial de las Letras que describió Pascale Casanova en su libro de idéntico título, pocas épocas ayudan a comprender mejor, más nítidamente, los marcos, con sus múltiples encrucijadas y tensiones, dentro de los cuales una sociedad debate el problema de las funciones de la escritura literaria en el camino hacia su conformación 
moderna, a su constitución como campo autónomo, desligado de su misión civilizadora de raíz iluminista. En la Europa del XIX este proceso queda ya culminado como respuesta a las dinámicas modernizadoras imparables que estableció en su cuerpo social la especialización del trabajo, de lo que resultaría la institucionalización de la labor artística e intelectual y su separación cuando no abierto enfrentamiento respecto a otros discursos, como el de la política, el de la técnica o el del mercado. Frente a ello, el caso hispanoamericano ofrece singularidades evidentes, efecto de lo que Julio Ramos designó como la modernización desigual de sus sociedades (Ramos). Ello motivaría que en un mismo escenario -incluso en un mismo autor o, yendo más allá, en un mismo textopugnaran con frecuencia las concepciones civilistas con los anhelos por alcanzar la definitiva autonomía de lo literario. De ahí que en este periodo abunden obras en las que se perciben no tanto las consecuencias de la llegada a la modernidad literaria como las tensiones desplegadas en el camino hacia su consecución.

Este panorama recorre de punta a punta el siglo XIX e incluso deja rastros en el modernismo finisecular, momento de máxima cercanía a tales metas. Sin embargo, son más ilustrativos ejemplos previos de lo que podrían denominarse puntos de tránsito o experiencias bisagra, momentos donde las coyunturas históricas y las encrucijadas ideológicas, políticas y culturales que enfrentaron los letrados hispanoamericanos dieron como resultado discursos en los que en sus mismas formas y estrategias de escritura se revelaban posiciones y perspectivas sobre lo literario a menudo contradictorias. De todos ellos, sin duda uno de los más interesantes es el que representó el romanticismo rioplatense de la primera mitad del siglo XIX. Me centraré en Esteban Echeverría por su representatividad en ese grupo y en $E l$ matadero por su singularidad, casi podría decirse que excepcionalidad, dentro de este periodo.

Si en Europa este proceso respondió a dinámicas internas de sus propias sociedades -analizadas por autores como Benjamin, Burgüer, Berman u Octavio Paz-, el contexto rioplatense de las primeras décadas tras la independencia ofrece la imagen de una sociedad en la que todo estaba por hacerse y donde la llegada de Rosas al poder suponía para los sectores liberales un regreso a las formas de gobierno de un pasado colonial con el que se quería romper. En esa situación, las elites letradas opuestas a Rosas reivindican la necesidad de llevar a cabo un proyecto de transformación del Estado en todas sus esferas, su refundación sobre nuevas bases. Europa -Francia e Inglaterra sobre todo- se constituye en el horizonte anhelado, tanto en lo referente a su desarrollo social como en cuanto a su cultura. El modelo a seguir es por tanto el de aquellas sociedades donde el arte, el mercado y la política van conquistando espacios separados y no pocas veces enfrentados. Pero aquí la situación es muy distinta, "una literatura nacional es tan indispensable como las ciencias, la religión y las instituciones en la formación de la comunidad", como ha señalado Beatriz Sarlo (xv) ${ }^{1}$; o en palabras de Julio Ramos: "Escribir, a partir de los 1820,

${ }^{1}$ La segunda parte del prólogo: "El doctrinario", fue escrita por Carlos Altamirano. 
respondía a la necesidad de superar la catástrofe, el vacío del discurso, la anulación de estructuras, que las guerras habían causado. Escribir, en ese mundo, era dar forma al sueño modernizador; era civilizar: ordenar el sinsentido de la 'barbarie' americana" (Ramos: 35). El problema, volviendo a Sarlo, era: “¿Cómo expresar literariamente una cultura y una sociedad que se juzga necesario fundar?" (xiv).

Mirarse al espejo de las sociedades europeas convierte esta literatura en máquina utópica con la que fabricar las imágenes de un futuro que por el momento está en otra parte. El discurso también está en otra parte, había que traerlo a suelo propio, y así el viaje a Europa, que Echeverría realiza en 1825, para los hombres del 37 fue, según Sarlo, un "peregrinaje patriótico", un viaje al "futuro de América". Vista esta situación, el problema de la emancipación del discurso, esa búsqueda de la expresión americana que ocupó a los literatos del XIX, debe eludir esquemas simplistas, basados exclusivamente en la mera importación de modelos, y abordarse desde una coyuntura más compleja. La originalidad literaria se impuso primero la separación respecto a la cultura española y de inmediato la búsqueda de nuevos paradigmas en lugares considerados ejemplos de progreso y desarrollo. Se produce así lo que Sarlo denomina "la originalidad de la importación cultural", consecuencia de una encrucijada intelectual que Echeverría, en su "Discurso de introducción a una serie de lecturas en el Salón Literario", de 1837, supo delimitar con claridad: "El saber e ilustración que poseemos no nos pertenece; es un fondo, si se quiere, pero no constituye una riqueza real, adquirida con el saber de nuestro rostro, sino debido a la generosidad extranjera" (Echeverría, 1991:154).

Esta lucidez en el análisis del estado de cosas nacional se muestra asimismo a la hora de abordar el problema de la creación literaria en ese contexto, cuando Echeverría la compara con la situación del escritor en las sociedades desarrolladas. En su respuesta a Alcalá Galiano, "La situación y el porvenir de la literatura hispanoamericana", de 1846, valora el proceso de la emancipación cultural de América respecto a España como "un trabajo lento, difícil, necesario para que pueda constituirse cada una de las nacionalidades americanas, trabajo indispensable para que surja una literatura americana que no sea reflejo de la española, ni de la francesa como la española". Y añade: "Sabría también que en América no hay ni puede haber por ahora literatos de profesión, porque todos los hombres capaces, a causa del estado de revolución en que se encuentran, absorbidos por la acción o por las necesidades materiales de una existencia precaria, no pueden integrarse a la meditación y recogimiento que exige la creación literaria, ni hallan muchas veces medios para publicar sus obras" (Echeverría, 1997: 171-172).

Sumando las ideas de ambas citas nos encontramos con una visión exacta de la situación de su país y asimismo con una conciencia muy clara de los factores y condiciones sociales necesarios que permitan el libre desarrollo de la cultura propia. Echeverría es consciente de que la literatura argentina de su tiempo se ve abocada a asumir una condición instrumental, a desplegarse como un apéndice más de la labor política y social, pero tiene muy claro al mismo tiempo que el futuro deseado y deseable para el logro de una verdadera emancipación cultural exigiría precisamente la inversión de tal situación: las alusiones a la profesionalización del literato y a las 
dificultades de publicación de las obras apuntan al proyecto de conquistar para la literatura un espacio específico dentro de los discursos sociales y a la necesidad de crear estructuras de producción cultural estables que faciliten la consecución de esos objetivos. Este cruce de caminos, donde se combinan la mirada al presente de la literatura nacional y el avistamiento de un futuro deseado que supondría la transformación de sus condiciones de producción y de su estatus, quizá pueda empezar a explicar algunas de las esferas problemáticas que un texto como $E l$ matadero plantea.

Nadie que se haya acercado a El matadero ha dejado de subrayar su excepcionalidad. Los interrogantes se agudizan por el hecho de su no publicación en vida del autor. Como se ha defendido con insistencia, es más que probable que respondiera a una decisión del propio Echeverría, dados la fama y prestigio adquiridos por sus composiciones poéticas. En 1837, la publicación de sus Rimas, en la que se incluye La cautiva, le convierte en el poeta nacional, e incluso antes de que esta última se publicara se recitaron en diversas ocasiones algunos fragmentos en el Salón Literario como ejemplo y modelo de los rumbos a seguir por parte de la literatura argentina. La cautiva responde en el plano estético al programa romántico que Echeverría ligó en todo momento a las necesidades políticas del momento: idealización, color local, uso de la naturaleza autóctona como cauce para la expresión del espíritu nacional y exaltación de las pasiones. Junto a ello, la lucha de María y Brian contra el desierto hostil alegoriza el combate por ocupar el vacío de civilización que ese territorio encarnaba, de ahí que en la arquetipización de los dos personajes al final del texto se revele cómo el autor otorga a la literatura una de sus funciones primordiales en las etapas primigenias de las civilizaciones: la construcción de mitos fundadores de la nacionalidad. Los referentes románticos que nutrieron sus propuestas poéticas: Byron, Hugo, Lamartine, Madame Stäel, mostraron a Echeverría un haz bastante amplio de actitudes, estrategias y funciones de la poesía y la literatura susceptibles de aprovechamiento para un proyecto nacional tanto en lo cultural como en lo político. El anticlasicismo, combinado en sus versos con una actitud iluminista respecto a la función literaria, plasma en este texto el paradigma principal de la poética romántica rioplatense que Echeverría encabezó.

En sus composiciones poéticas los diques de la ciudad letrada, ese territorio que Ángel Rama definió para trazar los cauces de la circulación cultural en Hispanoamérica, se mantienen firmes, la retórica romántica de sus versos se nutre de modelos de prestigio europeos importados a América. En el tratamiento de los temas que aborda, las soluciones estéticas -sustentadas en la idealización y la lógica de lo sublime como fuerzas básicas- e ideológicas - por sus intenciones civilizadorasresponden a las inquietudes y proyectos del sector exclusivamente letrado de la Argentina de su tiempo. En cambio, El matadero plantea de inmediato desafíos distintos y me atrevería a decir que nuevos a la pluma de su autor. Escrito en 1839 -nunca antes por las referencias históricas del texto- para algunos, a mediados de los cuarenta para otros, no fue publicado hasta 1871 gracias a su compañero de generación Juan María Gutiérrez, quien lo definiría como bosquejo o croquis de cuadro de costumbres y achacaría como un defecto "el desnudo realismo" de sus 
páginas, juicio este último interesante que apunta el carácter extraño de dicha estética en el momento de su redacción. Una de las discusiones que han llenado más páginas críticas sobre la obra ha sido la de su adscripción genérica: cuadro de costumbres, alegoría, ensayo o cuento, incluso la de mero borrador para una composición poética posterior, pero hay coincidencia general en lo relativo a su carácter híbrido por el cruce de géneros y la mezcla de discursos y estilos que despliega.

A partir de este consenso y teniendo en cuenta las frecuentes reflexiones de Echeverría sobre la necesidad de encontrar caminos para la consecución de una literatura americana -"mi obra no es local sino americana", afirmaría en 1844-, El matadero podría leerse como un experimento o laboratorio de pruebas a la hora de trasladar esas inquietudes al campo de la prosa. Piso un suelo resbaladizo y en lo que sigue habrá más hipótesis que convicciones rotundas; sin embargo, creo que hay rastros que permiten aventurarse por este cauce. Propongo entonces una lectura de $E l$ matadero que revele el modo en que las tensiones de época que merodean en torno al problema de la función de la literatura se escenifican en el interior del propio texto, no ya en una vertiente simplemente temática sino en el plano de su misma escritura.

Miguel Gomes, en "El género como invención: El matadero", breve epígrafe de su libro dedicado a Los géneros literarios en Hispanoamérica, apuntó la hipótesis de que El matadero, más que una obra en prosa perteneciente a un género concreto, sería más bien un texto en busca de un género. Para encuadrar tal caracterización dentro del proyecto literario de Echeverría, utiliza dos citas de su ensayo "Fondo y forma de las obras de imaginación", donde el autor de La cautiva defiende una actitud romántica basada en la ruptura con los modelos y formas antiguos sustituyéndolos por una poesía vigorosa y "multiforme", y que reivindica la mezcla de géneros como ejemplo de imaginación libre. Quizá, como señaló Juan Carlos Ghiano en su libro ' $E l$ matadero' de Echeverría y el costumbrismo, fuera el modelo del costumbrismo español, no tanto el de Larra como el de Estébanez Calderón y Mesonero Romanos y el de alguno de sus contemporáneos, el que El matadero buscara superar, pero, como el propio Ghiano expone, el resultado fue mucho más allá de esta simple revisión genérica para adentrarse en registros de escritura prácticamente inéditos en su época. Volviendo entonces al planteamiento de Gomes, El matadero podría leerse como texto que habla de su propia forma, que reflexiona y se interroga sobre las posibilidades de su escritura para encontrar un discurso válido, en primer término para su propio autor, respecto a aquello que se quiere contar, que en el caso de $E l$ matadero nos remite a zonas de la realidad nacional poco exploradas en su literatura. En momentos concretos de la obra se hacen explícitos tales desafíos.

"A pesar de que la mía es historia, no la empezaré por el arca de Noé y la genealogía de sus descendientes como acostumbraban hacerlo los antiguos españoles de América, que deben ser nuestros prototipos. Tengo muchas razones para no seguir ese ejemplo, las que callo por no ser difuso" (Echeverría, 1993: 91)². Así comienza El

\footnotetext{
${ }^{2}$ A partir de aquí, se indicará entre paréntesis en el texto la página de la que se extrae la cita.
} 
matadero, con el discurso poniéndose a sí mismo en escena mediante una estrategia de sentidos ideológicos muy claros. Lo que vendrá a continuación será historia pero conscientemente apartada de un paradigma del pasado: el de la crónica colonial, instituido como discurso por antonomasia del proyecto imperial español. La transgresión genérica desde la que el propio texto se define otorga así a la escritura un sentido liberador respecto a modelos previos que simbolizan el yugo político de los tiempos pretéritos. Esta actitud antiespañola continúa en las páginas siguientes con el repaso a un presente dominado por la religiosidad y la superstición, un clima espiritual que rememora el clima de la colonia, mediante un estilo de acentos bíblicos atravesado por la ironía. La mención inicial a Noé no es gratuita, en un Buenos Aires en plena cuaresma, "una lluvia muy copiosa" impide que lleguen al matadero del Alto las reses que debieran alimentar a la población. La reacción de esta refleja en la pluma de Echeverría los tiempos de oscurantismo que Rosas habría traído de nuevo: "Los beatos y beatas gimoteaban haciendo novenarios y continuas plegarias. Los predicadores atronaban el templo y hacían crujir el púlpito a puñetazos. Es el día del juicio, decían, el fin del mundo está por venir" (92-93).

Este juego domina las primeras páginas, dedicadas a la descripción irónica de la atmósfera conservadora del Buenos Aires rosista. Poco a poco van apareciendo las menciones y breves cuadros del matadero, y en ellos se detecta un curioso planteamiento narrativo. En la primera de estas referencias, justo antes del relato de los efectos de la falta de carne allí, leemos: "Acontecieron cosas que parecen soñadas" (94). En la segunda, previa a una descripción de corte objetivista de la ubicación en la ciudad del "matadero de la Convalecencia o del Alto" y de sus diferentes secciones, Echeverría señala: "Pero para que el lector pueda percibirlo a un golpe de ojo, preciso es hacer un croquis de la localidad" (98); inmediatamente después de esa panorámica, al enfrentarnos por vez primera con el trazo de las gentes que lo pueblan, leemos: "La perspectiva del matadero a la distancia era grotesca" (100). Y por fin, cuando escuchamos las voces de sus habitantes; es decir, cuando el texto nos invita a sumergirnos completamente en ese escenario, Echeverría señala justo al terminar este fragmento: "En fin, la escena que se representaba en el matadero era para vista, no para escrita" (103).

En esta última cita se hace explícito algo a lo que venían apuntando las citas anteriores y que ha interpretado muy lúcidamente María Rosa Lojo en La "barbarie" en la narrativa argentina del siglo XIX. Dice ahí: "Las escenas de El matadero se presentan como espectáculo 'animado y pintoresco'. En tanto espectáculo, es objeto de la mirada, y el narrador se siente obligado a presentarlo, con relieve irrefutable, ante los ojos del lector" (Lojo: 125). Y un poco más adelante concluye: "La vista se evalúa como suprema instancia de captación de lo real que excede las posibilidades de la escritura" (ibid.: 126). En efecto, a la hora de abordar la realidad degradada del matadero, hay un subtexto que de vez en cuando saca la cabeza y nos habla de la resistencia de esa realidad a ser atrapada por la escritura. Lo que ocurre allí son "cosas que parecen soñadas", necesitadas de una perspectiva distanciada, para ser vistas y no escritas; es decir, el discurso aborda un territorio de lo real para el que no se encuentran modelos y que exige mostrarlos tal cual son, escenas que exigen la 
inmediatez y por lo tanto no pueden mediatizarse. Lo paradójico e interesante es que en estos episodios es donde el relato levanta el vuelo literario, es entonces cuando el texto adquiere una dimensión narrativa incontestable que trasciende el mero cuadro costumbrista.

No creo que esa literariedad de la obra en su parte final fuera resultado de un ejercicio consciente por parte de Echeverría respecto a los posibles efectos de su escritura, pero sin duda a partir de la escapada del toro el relato muestra una eficacia narrativa muy notable e inédita hasta entonces. La agilidad del discurso, las apariciones secuenciadas de Matasiete, los paralelismos entre la caza del toro y la violencia contra el unitario, el accidente del inglés en la huida de la res, que anticipa la aparición del unitario, e incluso el diálogo entre este y el juez en las escenas finales, acercan la historia a los registros cuentísticos. No obstante, el hecho de que en esos momentos precisamente el discurso declare su renuncia a abordar determinadas espacios de lo real mantiene intactos nudos de sentido que han de ser destrenzados.

Volvamos al problema de las funciones de la literatura en la sociedad y el momento histórico de Echeverría, pues de ahí se desprenden zonas de conflicto y tensión que en El matadero permanecen irresueltas. El talento literario mostrado en las escenas ubicadas en el matadero entra en fricción con la misión que, dentro de la esfera pública de su época, se le atribuye al ejercicio de las letras. En palabras del propio Echeverría: "Dejar en herencia a su patria obras que la ilustren y la envanezcan" (Echeverría, 1991: 155). Esta asignación surge de la posición letrada y elitista que el propio Echeverría representa como pocos en su tiempo. En este marco, no resulta extraño que el microcosmos del matadero trate de narrarse a partir de una simulación, como si la mediación de la escritura no interviniera:

Como La cautiva, El matadero emerge de una sociedad ruralizada a la que representa en términos alegóricos, su ruralismo remite a la cuestión que Sarmiento considera central en Facundo, donde las posiciones políticas se dividen según líneas geográficas que, al mismo tiempo, son líneas culturales. En el relato de Echeverría, el matadero es un espacio de penetración de lo rural en lo urbano, una orilla (como dirá luego Borges) que, en vez de separar, comunica a la ciudad con la llanura: por lo tanto, un espacio abierto a la invasión rural del santuario urbano. Si la Argentina es una sociedad ruralizada, el matadero es la campaña bárbara peligrosamente cercana: trae el mundo rural a la ciudad. (Sarlo: xxv)

La cita de Sarlo dibuja con trazo preciso el mapa simbólico de la Argentina que $E l$ matadero estampa, el mundo bárbaro del campo ya está aquí, al lado, ya no en el desierto cuya lejanía permite describirlo, idealizándolo, mediante la impostación romántica de una voz poética que absorbe por completo el texto, como en La cautiva. Las voces de la barbarie, ahora tan cercanas, exceden las posibilidades de la ciudad letrada y la escritura ha de desplazarse fuera del feudo cerrado de las elites que la detentan. La palabra se traslada a los territorios de la voz, de una oralidad que amenaza con subvertir los valores y el sentido del proyecto literario. Tiene razón Sarlo cuando afirma que El matadero difícilmente "podía colocarse dentro del 
proyecto de Echeverría como escritor", al no ser "ni escrito político ni gran poema nacional" (xxiv-xxv), y seguramente haya que buscar la causa en una problemática que Julio Ramos encuentra en el Facundo, de Sarmiento, del que El matadero podría considerarse en este punto su antecedente claro: el modo en que se representa la voz del otro, ya que para Ramos, "la puesta en forma de la voz en la escritura es ideológicamente fundamental en el Facundo", tanto, añado, como lo es en El matadero. "Había que representar al otro -señala Ramos. Pero la 'confusión', la 'irregularidad' de la voz, era una fuerza que se resistía a la representación. Porque la barbarie es lo otro de la representación, es el exterior temido del discurso. Por eso no bastaba con 'escuchar' los registros de aquella realidad dispersa y amorfa. Había que someterla, ejercer la violencia de la forma sobre la irregularidad de la voz" (Ramos: 51), de ahí que en el Facundo "la escritura responde a la peligrosidad de la dispersión y del resabio 'oral', demarcando los cuentos, comentándolos, y subordinándolos la particularidad y ambigüedad del saber narrativo bajo la función generalizadora y universalizante de un discurso supuestamente "moderno"' (ibid.: 49-50). Como concluye Ramos, el orden social para Sarmiento solo asumiría "espesor en la escritura" y no en los tonos salvajes y fuera de control de la oralidad.

Ramos ilustra los mecanismos de control y estrategias de escritura mediante los cuales Sarmiento somete a la voz del bárbaro a una disciplina racionalizadora, por tanto letrada y desde luego ideológica, y algo parecido ocurre en la parte final de $E l$ matadero, cuando la voz autorial interviene para juzgar los hechos mostrados: "iQué nobleza de alma! ¡Qué bravura en los federales. Siempre en pandilla cayendo como buitres sobre la víctima inerte" (110). Las últimas líneas consagran definitivamente esta estrategia, cito solo una parte: "Los federales habían dado fin a una de sus innumerables hazañas. [...] Llamaban ellos salvaje unitario [...] a todo el que no era degollador, carnicero, ni salvaje, ni ladrón; a todo hombre decente y de corazón bien puesto" (114). En la misma estela, el lenguaje del unitario emerge en todo momento como contrapunto a la furia oral de los federales a través de una retórica letrada, como se ha subrayado, nada convincente, casi como un cuerpo extraño en la imagen veraz del escenario brutal del matadero que Echeverría dibuja.

Sin embargo, no me resisto a interponer un matiz muy relevante entre los textos de Echeverría y Sarmiento, ya mencionado para el caso del primero y que no encontramos en el Facundo. Me refiero nuevamente a esos momentos del discurso donde la escritura enuncia su retiro a la hora precisamente de retratar los espacios de la barbarie. La presencia de estas cuñas aporta un cierto factor de incertidumbre que cuestiona la hipotética convicción de su autor en cuanto al resultado de ese proceso de control de lo bárbaro dentro del texto. Por esta razón, considero convincente el argumento de la no publicación de la obra en vida de Echeverría por una decisión propia debido a las dudas que el resultado le suscitaría dentro de su proyecto literario. Quizá sea una explicación algo endeble, pero me parece que los elementos destacados dentro del texto para demostrarlo permiten sustentarla.

En fechas muy recientes, Ricardo Piglia destacó cómo, desde sus orígenes, la dialéctica entre civilización y barbarie que atraviesa la cultura argentina se habría articulado sobre la tensión entre la voz y la letra en una confrontación eminentemente 
política. Y señaló a El matadero como uno de los textos fundadores de la literatura argentina en relación a esa problemática:

El lenguaje que recrea al intelectual unitario es un lenguaje alto, literario, retórico que ha envejecido muchísimo. Mientras que el lenguaje que se usa para representar al otro, al monstruo, es un lenguaje muy vivo, que persiste y abre una gran tradición de representación de la voz y de la oralidad [...]. Entonces se podría pensar que esta tensión entre el mundo del letrado -el mundo intelectual-y el mundo popular -el mundo del otro- visto en principio de un modo paranoico pero también con fidelidad a ciertos usos de la lengua, está en el origen de nuestra literatura. (Piglia)

Piglia, al valorar la capacidad del autor letrado para reproducir la voz del bárbaro, sostiene que la oralidad actúa en la literatura como localizador de procesos sociales que se desarrollan fuera de los lugares institucionalizados, por tanto apartados del discurso político del poder e incluso enfrentados a él. El matadero se constituye en este punto como texto fundacional, pues en las voces que en él se oyen encontramos por primera vez en la tradición argentina una palabra específicamente literaria, al estar desligada de obligaciones sociales de otro rango y desplegando por ello una eficacia que aún perdura. Si Echeverría lo quiso así o no, no resta valor a ese legado ni cuestiona en lo más mínimo sus virtudes literarias. Víctor Hugo, en el prefacio a Cromwell, considerado por muchos como un texto capital para explicar las ideas de Echeverría, dibujó el proceso al que la literatura debía acompasarse en la evolución de las civilizaciones: "La sociedad empieza por cantar lo que sueña, después refiere lo que hace, y al fin describe lo que piensa". Quizá Echeverría trató llevar a cabo en $E l$ matadero la culminación de este camino, no optando por uno solo de estos procedimientos sino tratando de cantar, referir y describir a la vez los sueños, actos y pensamientos que su país en ese momento de su historia le requería. Quizá las dudas le vencieron, pero una cosa es segura: esas mismas dudas impidieron a sus contemporáneos disfrutar de una obra extraordinaria.

\section{BIBLIOGRAFÍA}

ECHEVERRÍA, Esteban.

1991 Obras escogidas. Caracas: Biblioteca Ayacucho.

1993 El matadero. La cautiva. Ed. de Leonor Fleming. Madrid: Cátedra.

1997 "La situación y el porvenir de la literatura hispanoamericana", en Teodosio Fernández. Teoría y crítica de la emancipación hispanoamericana. Alicante: Instituto de Cultura Alicantina Juan GilAlbert.

GHIANO, Juan Carlos.

1968 'El matadero' de Echeverría y el costumbrismo. Buenos Aires: CEAL. 
GOMES, Miguel.

1999 "El género como invención: El matadero", en Los géneros literarios en Hispanoamérica: teoría e historia. Pamplona: EUNSA.

LoJo, María Rosa.

1994 La "barbarie" en la narrativa argentina del siglo XIX. Buenos Aires: Corregidor.

PIGLIA, Ricardo.

2001 “Qué va a ser de ti?”, en “Tres propuestas para el próximo milenio y cinco dificultades"

RAMOS, Julio.

http://www.pagina12.com.ar/2001/suple/Radar/01-12/01-12-23

2003 Desencuentros de la modernidad en América Latina. Santiago de

SARLO, Beatriz. Chile: Cuarto Propio.

1991 "El poeta", primera parte del prólogo a las Obras escogidas de Esteban Echeverría. Caracas: Biblioteca Ayacucho. 